\title{
O AGRONEGÓCIO, A EXPANSÃO DA TRANSGENIA E A EXPROPRIAÇÃO DE TERRAS NO POLO JUAZEIRO/PETROLINA
}

\author{
Agribusiness, expansion of transgeny and land expropriation in the Juazeiro / Petrolina polo
}

\section{El agronegocio, la expansión de la transgenia y la expropiación de tierras en el polo Juazeiro / Petrolina}

\footnotetext{
${ }^{1}$ Graduanda em Geografia pela Universidade de Pernambuco - UPE, Brasil, Email - Amorimanajulia91@ gmail.com.

${ }^{2}$ Doutora em Geografia pela Universidade Federal do Sergipe - UFS, Brasil, Professora adjunta da Universidade de Pernambuco, email - áurea.souza@upe.com.
}

Ana Júlia de Souza Amorim ${ }^{1}$ https://orcid.org/0000-0001-8508-1804 Raimunda Áurea Dias de Sousa ${ }^{2}$ https://orcid.org/0000-0002-4646-4500

\begin{abstract}
Resumo
A expansão da agricultura irrigada em Petrolina centrada na política do agronegócio tem contribuído para efetivar o aumento da produção e produtividade via apropriação/expropriação com o intuito de transformar o cultivo, especialmente, do milho, em mercadoria - valor de troca. Nesse sentido, o objetivo da presente pesquisa é compreender como as terras são apropriadas pelo agronegócio, especialmente, para a expansão da transgenia cujo intuito é valor de troca - mercadoria, contraditoriamente, tem provocado a expropriação dos camponeses do bem natural (terra) e do cultivo agroecológico do milho para satisfação das necessidades humanas, valor de uso.
\end{abstract}

Palavras-chave: Conflitos. Sementes. Terra.

\begin{abstract}
The expansion of irrigated agriculture in Petrolina centered on agribusiness policy has contributed to the increase of production and productivity through appropriation / expropriation in order to transform the cultivation, especially of corn, into commodity - exchange value. In this sense, the objective of the present research is to understand how land is appropriated by agribusiness, especially for the expansion of transgenics whose purpose is exchange - commodity value, contradictorily, has caused the expropriation of the peasants of the natural good (land) and the agroecological cultivation of corn to satisfy human needs, use value.
\end{abstract}

Keywords: Conflicts. Seeds. Earth. 


\section{Resumen}

La expansión de la agricultura de regadío en Petrolina centrada en la política de agronegocios ha contribuido al aumento de la producción y de la productividad a través de la apropiación / expropiación con el propósito para transformar el cultivo, especialmente del maíz, en valor de intercambio de productos - mercadería. En este sentido, el objetivo de la presente investigación es comprender cómo las tierras son apropiadas por los agronegocios, especialmente para la expansión de los transgénicos cuyo propósito es el intercambio comercial: el valor de los productos básicos, contradictoriamente, ha provocado la expropiación de los campesinos del bien natural (la tierra) y cultivo agroecológico del maíz para satisfacer las necesidades humanas, valor de uso.

Palabras clave: conflictos. Semillas. Tierra.

Recebido em: 24/10/2019

Aceito para publicação em: 05/12/2019

\section{Introdução}

A política do agronegócio ${ }^{3}$, marcada pela expansão da agricultura irrigada em Petrolina, tem contribuído para efetivar o aumento da produção e produtividade via apropriação/expropriação de terras com o intuito de transformar o cultivo, especialmente, do milho, em mercadoria - valor de troca. Esse, ao se transformar em sementes transgênicas, evidencia um território em disputa entre agronegócio e agricultura familiar/camponesa quando não somente a terra é apropriada, mas é retirada dos trabalhadores a autonomia de cultivo de uma semente historicamente produzida por eles sem ser geneticamente modificada em laboratórios.

Para atender à política de irrigação, alterações significativas no campo foram realizadas no Polo Juazeiro/Petrolina ordenadas pela política macroeconômica externa e pela política agrícola interna, mudando completamente o sentido da produção, assim como a escala de produção desde a concretude em Petrolina-PE do Perímetro Irrigado Bebedouro nos anos de 1960. Todavia, é nos anos de 1990, com o Perímetro Irrigado Senador Nilo Coelho que o agronegócio se consolida, mediante as exportações de frutas frescas e com ela a exportação da água, proveniente do rio São Francisco.

Nesse sentido, de acordo com Gama da Silva (2009, p.84), as frutas produzidas no Polo tiveram uma trajetória ascendente com pequenas variações no volume exportado em função da instabilidade das políticas cambiais e do próprio mercado externo, até meados dos anos de 1990. "Entretanto, é a partir de 1997 que essa tendência se consolida e a participação

\footnotetext{
${ }^{3}$ Nada mais é do que um marco conceitual de que delimita os sistemas integrados de produção de alimentos, fibras e biomassa operando desde o melhoramento genético até o produto final. (MARCOS, 2008 p.196).
} 
das principais frutas produzidas voltadas para mercado externo (uva e manga) passa a contribuir com $90 \%$ do volume das exportações do país".

O agronegócio, considerado um "novo" modelo, traz como alternativa o uso de tecnologia seguida de pesquisas e de capacidade de gestão - fatores considerados decisivos para competição no mercado mundial. Assim, apropriam-se de terras ou contratam os empreiteiros que arrendam terras e provêm o maquinário, a equipe e os agroquímicos necessários para estimular a produção das commodities ${ }^{4}$, especialmente, o milho associada ao uso excessivo da terra e água, pois "a hegemonia do agronegócio sustenta-se no modelo agroexportador de commodities, em grande escala e com uso intensivo de agrotóxicos e transgênicos, não permitindo outra forma de produção agrícola.” (BARROS, 2018, p.183).

Dentro dessa perspectiva, em 2013, é instalada a empresa Monsanto (hoje adquirida pela Bayer) em Petrolina, notadamente voltada para a produção de milho transgênico, cuja finalidade centra-se em elevar a produção para atender às necessidades da população que de acordo com a empresa nos próximos 50 anos a contar de sua instalação em Petrolina, a sociedade precisará produzir mais alimentos do que nos últimos 10 mil anos somados, para atender às necessidades da crescente população mundial. Sendo assim, justifica-se sua instalação e a apropriação de terras em Petrolina, pois é possível desenvolver pesquisas e plantar esse cultivo o ano inteiro em virtude da água do rio São Francisco e as condições climáticas.

Com o desenvolvimento da semente de milho transgênico em laboratório para, em seguida, ser cultivado a princípio em um espaço de 60ha e, posteriormente, em outros espaços apropriados pela Monsanto em Petrolina e Juazeiro, a empresa tem conseguido fornecer mudas do milho para todo o país, elevando, assim, a produção da semente.

Nesse contexto, o objetivo deste trabalho é compreender como as terras são apropriadas pelo agronegócio, especialmente, para a expansão da transgenia cujo intuito é valor de troca - mercadoria, contraditoriamente, tem provocado a expropriação dos camponeses do bem natural (terra) e do cultivo agroecológico do milho para a satisfação das necessidades humanas, valor de uso.

A metodologia estruturou-se em torno de três eixos de operacionalização: a) a organização de uma pesquisa bibliográfica, com base autores como: Teubal (2008), Bombardi (2011), Sousa (2013), Fernandes (2017) e Barros (2018); b) a realização de trabalho de campo

\footnotetext{
${ }^{4} \mathrm{O}$ termo commodity, que em português significa mercadoria, tem longa tradição de uso tanto na economia política quanto em sua crítica. Diz-se que um recurso, um bem ou um serviço torna-se uma mercadoria quando é comprado e/ou vendido no mercado, adquirindo, portanto, um preço (DELGADO, 2012 p. 135).
} 
em empresa que produz milho transgênico; c) a construção de um banco de dados estatísticos a partir dos dados coletados em sites como: Censo Agropecuário IBGE - 2006 e resultados preliminares de 2017, Ministério da Agricultura, Pecuária e Abastecimento, MST (Movimento dos Trabalhadores Rurais Sem Terra); vinculados à elaboração de gráficos, tabelas e mapas que evidenciem as terras apropriadas para a produção de semente transgênica e a diferença entre elas.

Detectou-se que o espaço agrário tem sofrido profundas alterações com a imposição das sementes geneticamente produzidas em laboratório centrado no discurso da produtividade, competividade e garantia de alimentos contrários às sementes produzidas pelos agricultores familiares e camponeses que, além de não ocasionar enfermidades, fazem parte de um modo de vida porque traz dignidade para quem produz e quem consome os alimentos.

\section{A relação entre agronegócio e transgenia}

A chegada do agronegócio no Brasil, em 1990, inseriu uma nova realidade no campo, que, de acordo com Teubal (2008), fortalece uma "agricultura sem agricultores", pois o objetivo desse modelo é a produção e o lucro, buscando-se as mais variadas maneiras de potencializá-lo, dentre elas a substituição do homem por máquinas, em vez de se utilizar dessas ferramentas tecnológicas para possibilitar um trabalho mais digno.

De acordo com Silva e Sousa (2018), apesar de ser um dos ramos da economia que mais agrega valor ao PIB brasileiro, ele não consegue produzir alimentos saudáveis para suprir a necessidade da população, pois é baseado na monocultura para a exportação. Por isso, o mercado vai definir o que deve ser produzido, não se levando em consideração as necessidades dos que vivem no campo.

Nesse sentido, são utilizadas as sementes transgênicas ${ }^{5}$, definidos como organismo que recebe, em seu genoma, uma sequência de DNA que foi previamente manipulada em laboratório por técnicas especiais. Essa alteração ultrapassa as fronteiras da natureza, pois o cruzamento é entre reinos diferentes, ou seja, não aconteceria de maneira natural, diferentemente das sementes crioulas ${ }^{6}$, que são reproduzidas de maneira natural e podem ser armazenadas por vários anos.

\footnotetext{
${ }^{5}$ É um método de criação de sementes que não envolve processos da natureza, sendo realizado mediante engenharia genética. Esse método modifica os genes das plantas, que recebem genes de outros organismos os quais, muitas vezes, nem pertencem ao reino vegetal, como vírus e agro bactérias, entre outros (MAIÇÁ, 2012 p. 704).

${ }^{6}$ É o material cultivado localmente, geração após geração, o que determina a sua adaptação à comunidade onde está sendo cultivado, pelos camponeses que ali habitam (MAIÇÁ, 2012 p. 703).
} 
Fernandes (2017) afirma que o avanço do modelo capitalista sobre o campo inaugurou diversos métodos de artificialização das técnicas produtivas com o objetivo de aumentar a margem de acumulação de riquezas por parte dos agroindustriais, proporcionando consequências nefastas compartilhadas entre todos e não apenas pelos acumuladores do agronegócio.

Assim, em 2005, foi inaugurada a lei de biossegurança, CTNBio ${ }^{7} 11.105$. Sendo de importância estratégica para o agronegócio brasileiro e mundial, pois vem fortalecer a produção tolerante aos herbicidas, no caso, os transgênicos (SILVA \& SOUSA, 2016, p.4).

Diagrama 1- Fusões das empresas do mercado de sementes e agrotóxicos

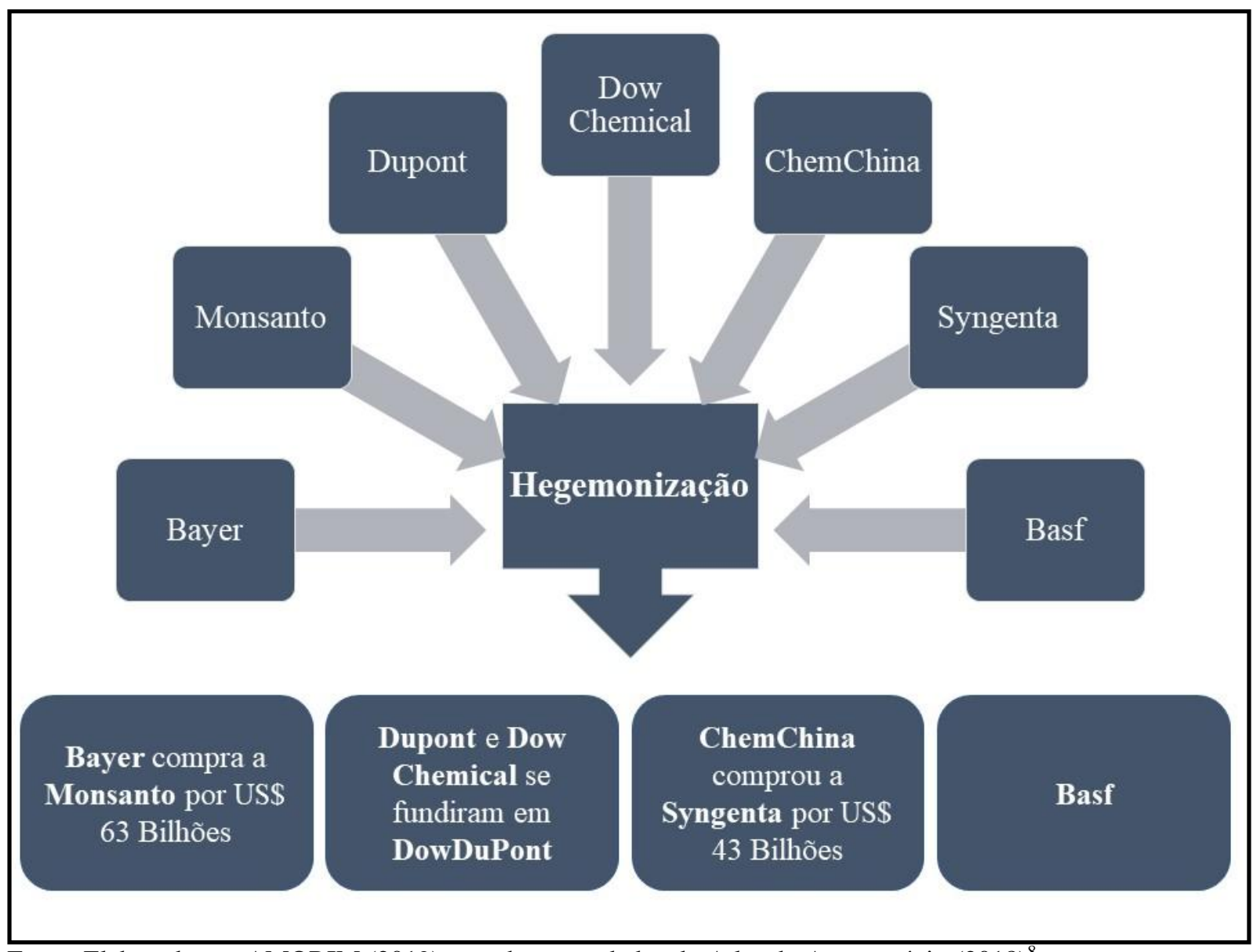

Fonte: Elaborado por AMORIM (2019), com base em dados do Atlas do Agronegócio (2018)

O agronegócio tem se apropriado do campo com o intuito de transformá-lo em um negócio lucrativo diferentemente da agricultura camponesa. Como aponta Fernandes (2017,

\footnotetext{
${ }^{7}$ Comissão Técnica Nacional de Biossegurança

${ }^{8}$ Atlas do Agronegócio disponível em: < https://br.boell.org/pt-br/2018/09/04/atlas-do-agronegocio-fatos-e-numeros-sobrecorporacoes-que-controlam-o-que-comemos > acesso em: 30/05/2019
} 
p.4), "no agronegócio não há cultura, pois não há povo, a relação homem-natureza é mediada pelos valores do mercado, do negócio"

Conforme Sousa (2013b), tem ocorrido a apropriação do campo pelo mercado;

[...]o campo passou a ser alvo das grandes empresas interessadas em produzir aquilo que está sendo requerido pelo mercado. Assim, compram terras ou contratam os empreiteiros que arrendam terras e provêm o maquinário, a equipe e os agroquímicos necessários para estimular a produção das commodities associada ao uso excessivo da água (SOUSA, $2013^{\mathrm{b}}$, p.164).

A maneira encontrada pelas empresas para hegemonizar o domínio sobre esses artefatos, que são protegidos por patentes, reduzindo a um pequeno grupo o acesso ás informações que são fundamentais para o entendimento das consequências dessas, para aqueles que consomem é a monopolização das sementes transgênicas e agrotóxicas por meio da fusão das empresas como é apresentado no diagrama 1.

No diagrama 1, é apresentada a fusão das empresas que realizam a produção de sementes transgênicas e agrotóxicos, aumentando o monopólio agrícola mundial, pois, juntas, essas megaempresas detêm o domínio desse mercado. A Bayer, por exemplo, passou a ter um terço da produção global de sementes e um quarto de agrotóxico.

Nesse sentido, Bombardi sustenta que:

O monopólio exercido pelas transnacionais do setor agroquímico é uma expressão clara da grande e, poderíamos dizer, específica forma do capital se reproduzir na agricultura. Esta especificidade da reprodução do capitalismo vinculado à agricultura se dá de forma indireta. Ou seja, as grandes indústrias voltadas para a agricultura não precisam produzir diretamente no campo, mas encontram formas de subordinar a produção no campo (BOMBARDI, 2011, p. 2).

A relação agronegócio e transgenia, não está apenas na utilização da semente modificada, mas esse sistema tem aumentado a insegurança alimentar por outro ponto, o consumo de agrotóxicos, que está aumentando a cada ano no Brasil. A liberação desses tem se intensificado nos últimos anos como mostra o gráfico 1. 
Gráfico 1- Número de agrotóxicos aprovados por ano no Brasil (2005 a 2018)

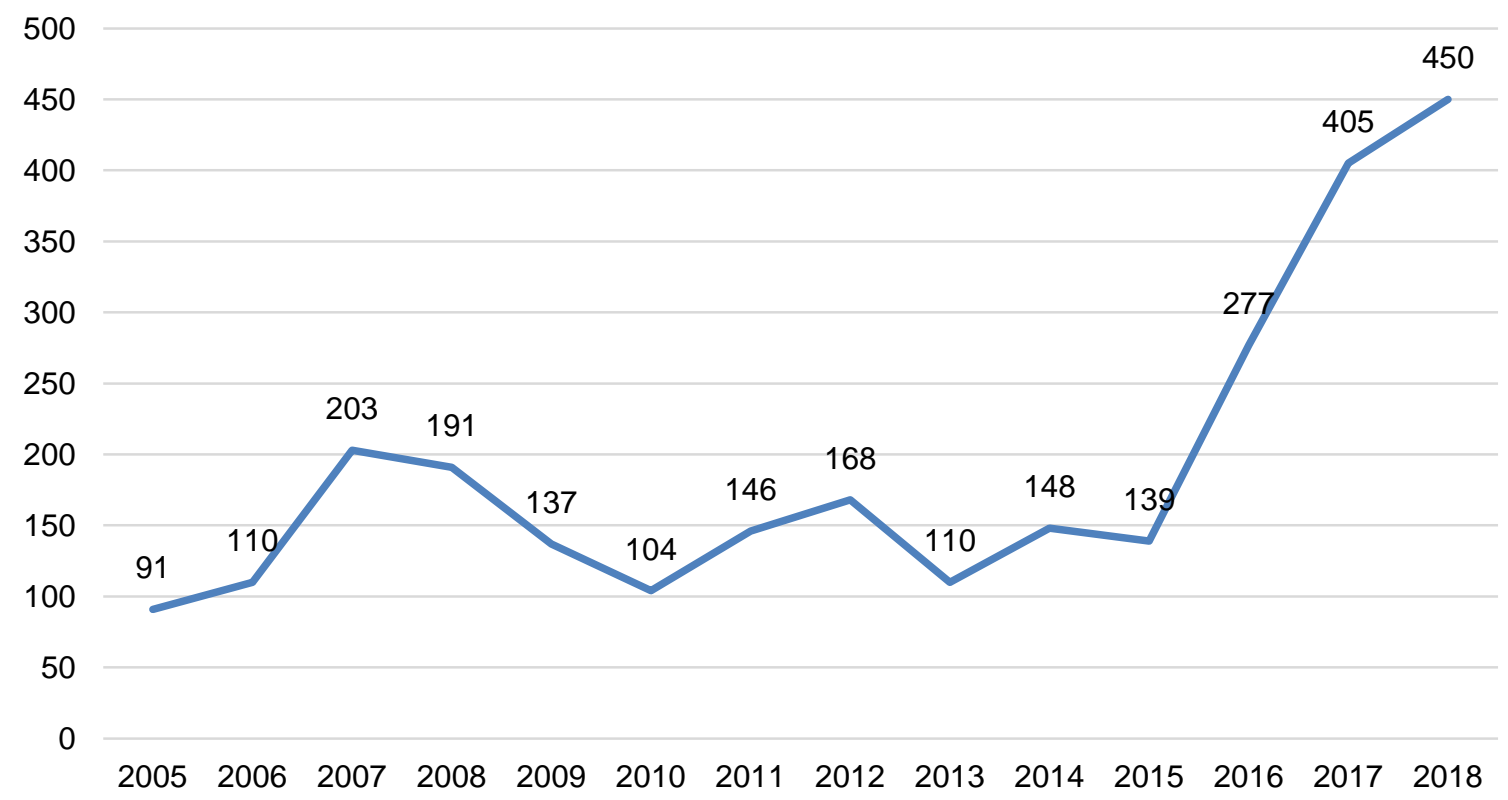

Fonte: Ministério da Agricultura, Pecuária e Abastecimento ${ }^{9}$

Para compreender o gráfico 1, é necessário relacioná-lo aos acontecimentos do âmbito político, pois, de acordo com Bombardi (2019), o aumento no número de agrotóxicos aprovados no Brasil está ligado ao fortalecimento da Bancada Ruralista concentradora de terra, uma importante aliada no fortalecimento de Governos como o de Michel Temer, e agora, Jair Bolsonaro. Apesar do número menor de identificados com a bancada eleitos, eram 218 deputados, 99 foram reeleitos, reduzindo para menos da metade os representantes da bancada na câmara dos deputados; no senado, o cenário não foi diferente, eram 27 , e permaneceram 18 uma redução de aproximadamente 35\% dos parlamentares. Entretanto o quadro conservador permaneceu, pois o que ocorreu foi a disseminação dos candidatos eleitos nos diversos partidos, situação que não impede a adesão dos parlamentares eleitos à Frente parlamentar da agropecuária (FPA). Além do mais, a FPA se aliou ao atual presidente, que, simplesmente, pertence ao partido com o maior crescimento em sua representatividade nas eleições de 2018, PSL, partido conservador que tem colaborado com as ambições dos ruralistas.

Até setembro de 2019, já foram registrados 325 agrotóxicos; 7 deles têm princípio ativo novo, porém são igualmente tóxicos aos já usados no país. Entre eles, está o glifosato,

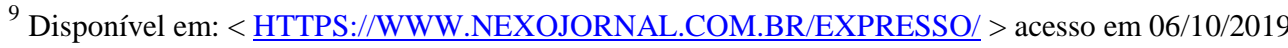

V. 3, n 3, 2019 http://periodicos2.uesb.br/index.php/geo
}

Este é um artigo de acesso aberto sob a licença Creative Commons da CC BY 
um dos defensivos agrícolas que o país mais compra e que a Organização Mundial da Saúde alerta que pode causar câncer. Na análise da Greenpeace, pelo menos $26 \%$ desses defensivos liberados já foram banidos pela União Europeia.

A utilização tanto da transgenia, como também do agrotóxico é feita com a promessa de produzir mais alimentos. Entretanto, o que, de fato, acontece é a necessidade de aumento nas áreas de produção, para efetivar essa produtividade agrícola. Consequentemente, proporcionando apropriação das terras pelo agronegócio e expropriação do cultivo agroecológico, pois, para esse sistema, a quantidade de terra nunca é suficiente. Com o intuito de fortalecer-se são realizadas diversas propagandas, apresentando o lado positivo desse negócio, que o agronegócio tem transformado a alimentação; entretanto, a realidade está bem longe da apresentada.

Nesse contexto, Sousa afirma em relação à consolidação da fruticultura no vale que:

[...]as terras do vale destinadas ao trabalho camponês se metamorfoseassem em terras de negócios de modo a auferir renda territorial que por sua vez é um lucro extraordinário, sobre acima do lucro médio, que resulta do trabalho excedente, da mais-valia originada na produção e efetivada na circulação das mercadorias, pois não se trata de apropriação que começa com o capital, mas que se transforma em capital (SOUSA, 2013 ${ }^{\mathrm{a}}$, p. 144).

O agronegócio utiliza-se dos transgênicos com a promessa de redução do consumo de agrotóxicos e aumento da produtividade; entretanto, na prática, detecta-se que ocorreu o aumento no seu uso de 2000 a 2010 em 15\%, devido ao cultivo muito grande de soja, milho e cana, que necessitam, nos moldes do agronegócio, de muitos herbicidas diferentemente do que ocorre na agricultura camponesa, em que se tem algo semelhante ao que ocorre na natureza, com a associação de vários cultivos e um manejo natural no qual não se utiliza algo para eliminar as demais espécies. As empresas detentoras da patente dos transgênicos, produzem-nos resistentes aos herbicidas. Sendo assim, junto com a semente, o produtor também compra o agrotóxico para eliminar qualquer outra espécie que surja na plantação, situação essa que não demanda tanto dinheiro quanto no sistema manual, porém reduz a empregabilidade da agricultura e aumenta a insegurança alimentar.

\section{A expropriação de terras dos camponeses para a produção de transgênicos}


Petrolina e Juazeiro estão inseridas em uma região de baixo índice pluviométrico se comparadas as demais; entretanto, a partir da irrigação tem conseguido produzir diversos alimentos durante o ano inteiro graças as águas do rio são Francisco. Assim, a partir da política de irrigação, percebe-se a apropriação de terras por parte de empresas no Vale como é o caso da Monsanto, atual Bayer. Essa é hoje uma das maiores produtoras mundiais de agrotóxicos e milho transgênicos e, para isso, tem expandido as suas áreas de cultivo.

Apesar do valor da semente, muitos agricultores tem optado pelo o transgênico, pois, segundo eles, o custo é menor, pois só precisam comprar a semente que apresenta um valor elevado. Mas, na realidade, o que, de fato, acontece é a subordinação da agricultura ao capital como apresenta Bombardi (2011):

A reprodução do capitalismo no campo se dá através da subordinação da renda da terra (seja ela camponesa ou não) ao capital. Esta apropriação da renda da terra é realizada quando se utiliza um insumo industrializado para produzir. Com o advento dos transgênicos, esta subordinação fica "selada" em todas as suas pontas. Desde as sementes, passando pelos fertilizantes e chegando, finalmente, ao veneno "adequado" à semente comprada (BOMBARDI, 2011, p.2-3).

Os camponeses, apesar de produzirem os alimentos essenciais para a população, não recebem o devido reconhecimento e investimento do estado, pois para este a produção que tem dado resultado é a feita pelo agronegócio a que difere da explicação de Barros:

O que se verifica, nessa realidade, é a expansão do capital no campo, pois essa é sua lei: a da reprodução e acumulação crescente e ampliada. O aspecto mais relevante da expansão do capital no campo é exatamente a expropriação dos trabalhadores rurais de suas terras e sua transformação em trabalhadores livres, ou seja, libertos da propriedade da terra, tendo apenas sua força de trabalho e sua capacidade de trabalhar, para se tornarem assalariados e/ou outras formas de relação de trabalho com a grande empresa capitalista rural, acrescido da renda da terra (BARROS, 2018, p.193).

O interesse que permeia a região do vale do são Francisco tem feito com que os pequenos camponeses não tenham acesso às áreas com possibilidade de produção o ano inteiro, e precisem buscar uma outra renda, fazendo com que eles experimentem o assalariamento e acabem sendo absorvidos aos poucos pelo capitalismo, em anos de seca no qual não conseguem produzir; acabam perdendo suas sementes tradicionais que são naturalmente adaptadas às adversidades de cada região. Por isso, é fundamental a construção 
de bancos de sementes para garantir a biodiversidade; porém, não é de interesse do governo investir na manutenção da agricultura familiar.

A análise de Sousa (2013a) confirma esse processo de exclusão em relação ao vale, no qual a produção e produtividade têm aumentado em virtude do uso das mais modernas tecnologias no campo, porém abrangendo somente o espaço rural transformado em território pelo capital, chamado, contraditoriamente, "Perímetro Público de Irrigação", visto que ele não é público, e uma minoria tem acesso ao mesmo.

O gráfico a seguir traz justamente a mudança no perfil agrícola da cidade de Petrolina, que tem concentrado as áreas de produção de milho, devido ao custo benefício, já que com a perda da semente crioula ou substituição da mesma pela transgênica, o produtor se torna refém de empresas como a Bayer e, consequentemente, tem a renda de sua terra subordinada ao capital.

Gráfico 2 - Comparativo do número de estabelecimentos agropecuários com lavoura de grão de milho

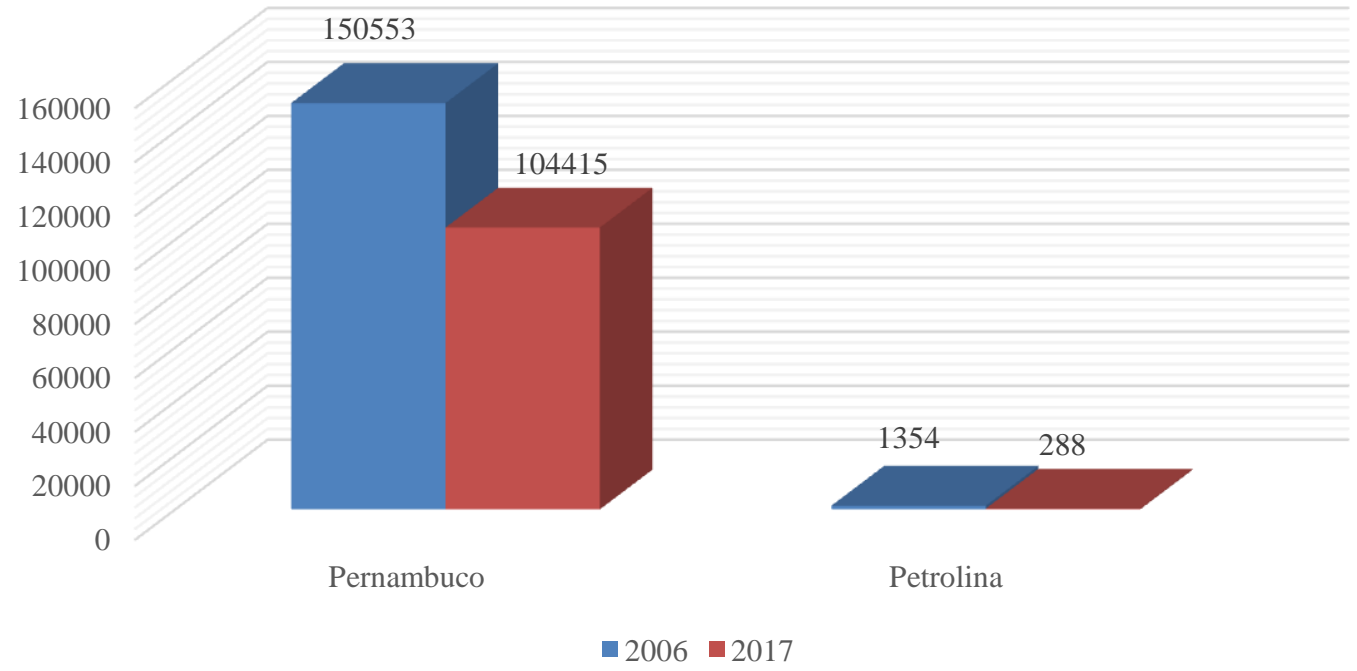

Fonte: Dados do censo agropecuário de 2006 e 2017 (Dados preliminares). Elaborado por AMORIM (2019)

De acordo com o gráfico 2, o estado de Pernambuco, de 2006 para 2017, manteve equilibrado o número de estabelecimentos com produção de milho, enquanto a cidade de Petrolina reduziu consideravelmente o número de estabelecimentos com esse cultivo, mesmo com a presença da Bayer na região, o que se justifica por a mudança no perfil de produção das áreas irrigadas, visando ao mercado externo, pouco investimento nos cultivos agroecológicos, 
encarecimento dessa produção com a utilização de transgênicos e concentração dos estabelecimentos.

Conforme Barros (2018), o capital se territorializou e intensificou a expropriação e a expulsão dos camponeses para as cidades a partir da instalação de grandes complexos agroindustriais e via monocultura para exportação, ampliando e reproduzindo o capital no campo.

Consequentemente, a presença da Bayer na região tem intensificado a expropriação do cultivo agroecológico, subordinando o camponês ao capital, extraindo a renda da terra através dos insumos industriais e expulsando-o para a cidade onde se tornará mão de obra assalariada produtora de riqueza para a mesma empresa em muitos situações, concentrando, o domínio dos meios de produção.

\section{Considerações finais}

A concentração de terra para o agronegócio e a agricultura familiar/camponesa sujeita às pressões do mercado repercute na produção de milho transgênico e, contraditoriamente, na expropriação dos sujeitos do campo.

Desse modo, necessita-se de autonomia dos pequenos agricultores em produzir cultivo voltado para sementes crioulas - milho, feijão e mandioca como condição de alimentos, evitando, assim, a miséria dos que vivem no campo.

Assim, as sementes transgênicas para o agronegócio são uma forma de poder, de dominação, ou seja, concentração de terras efetivadas pelas grandes corporações produtoras de alimentos, como é o caso da Monsanto, bem como da apropriação da autonomia de cultivos desenvolvidos pelos agricultores familiares/camponeses. Todavia, isso acirra o conflito entre agronegócio e agroecologia.

\section{Referências}

BARROS, F. I.. O agronegócio e a atuação da burguesia agrária: considerações da luta de classes no campo. Serviço Social \& Sociedade. São Paulo,2018, n.131, p.175-195.

BOMBARDI, L. M.. Artigo - O aumento do número de agrotóxicos aprovados no Brasil. Nexo, Website de Nexo, p. 1 - 4, 05 fev. 2019.

BOMBARDI, L. M.. Intoxicação e morte por agrotóxicos no Brasil: a nova versão do capitalismo oligopolizado. Boletim Data Luta, v. 45, p. 1-21, 2011.

DELGADO, N. G.. Commodities agrícolas. In: Dicionário da Educação do Campo. / Organizado por Roseli Salete Caldart, Isabel Brasil Pereira, Paulo Alentejano e Gaudêncio 
Frigotto. - Rio de Janeiro, São Paulo: Escola Politécnica de Saúde Joaquim Venâncio, Expressão Popular, 2012.

FERNANDES, L.. O uso de agrotóxicos na produção de alimentos é a expressão do avanço do modelo capitalista no campo. Disponível em: < www.mst.org.br/2017/04/11/ouso-de-agrotoxicos-na-producao-de-alimentos-e-a-expressao-do-avanco-do-modelocapitalista-no-campo.html > acesso em: 03/09/2019.

GAMA SILVA, P. C.. Dinâmica e Crise da Fruticultura Irrigada no Vale do São

Francisco. In: Diversificação dos espaços rurais e dinâmicas territoriais no Nordeste do Brasil. Org. Aldenor Gomes da Silva, Josefa Salete Barbosa Cavalcanti e Maria de Nazareth B. Wanderley. João Pessoa: Zarinha Centro de Cultura, 2009.

MAIÇÁ, E. D.. Sementes. In: Dicionário da Educação do Campo. / Organizado por Roseli Salete Caldart, Isabel Brasil Pereira, Paulo Alentejano e Gaudêncio Frigotto. - Rio de Janeiro, São Paulo: Escola Politécnica de Saúde Joaquim Venâncio, Expressão Popular, 2012.

MARCOS, V. de. Agricultura e Mercado: Impasses e Perspectivas para o Agronegócio e a produção Camponesa no Campo Latino-Americano. In: Campesinato e Territórios em Disputa org. Eliane Tomiasi Paulino \& João Edimilson Frabrini. $1^{\mathrm{a}}$ Ed., São Paulo: Expressão Popular: UNESP: Programa de Pós Graduação em Geografia, 2008.

SILVA, B. B. de R.; SOUSA, R. Á. D.. O agronegócio, os transgênicos e a questão alimentar: uma análise sobre o polo Juazeiro/Petrolina. Revista Geoaraguaia, Barra do garças, 2018, v. 8, n. 3, pag. 1-16.

SOUSA, R. Á. D.. A renda fundiária e o trabalho - a realidade da agricultura irrigada no Vale do São Francisco In: CONCEIÇÃ̃, Alexandrina Luz; SOUSA, Raimunda Áurea Dias de (Org). O capital e a ocupação de Terras/Territórios. São Cristovão: Editora UFS, 2013a. P. 143-164.

SOUSA, R. A. D.. O agro-hidronegócio no vale do são Francisco: território de produção de riqueza e subtração da riqueza da produção. 2013. 356 f. Tese (Doutorado) -Curso de Geografia, Núcleo de Pós-Graduação em Geografia, Universidade Federal de Sergipe, São Cristóvão-SE, 2013b. Cap. 3. p.164.

TEUBAL, M.. O campesinato frente à expansão do agronegócio na América Latina. In: PAULINO, Eliane Tomiasi; FABRINI, João Edimilson (Org). Campesinato e territórios em Disputa. São Paulo: Expressão Popular: UNESP: Programa de Pós-Graduação em Geografia, 2008. p. 139-160.

Nota:

Este trabalho é resultante de pesquisa cientifica com bolsa de iniciação cientifica da Universidade de Pernambuco- UPE-BRASIL

Agradecimentos

À UPE - pesquisa de Iniciação Cientifica/2019, UPE Campus Petrolina- Brasil 